\title{
10 health stories that mattered: Oct. 11-17
}

- Ebola dominated health news in Canada this week. Canada may contribute another $\$ 30$ million to the fight against Ebola, reports The Globe and Mail. Health Canada and the Public Health Agency of Canada expressed high hopes for clinical trials for a Canadian-made Ebola vaccine. Two Ontario patients with Ebola-like symptoms tested negative for the virus (in Ottawa and Belleville). Health officials stated they were prepared for Ebola in Ontario, British Columbia, Alberta and Newfoundland and Labrador. The Canadian Federation of Nurses Unions and several other nurse organizations, however, claim frontline health workers lack the training and protective equipment needed to safely treat patients with Ebola.

- The price of generic drugs remains too high in Canada despite moves to reduce costs through bulk-buying, according to a study in Open Medicine by the University of Ottawa and the Bruyère Research Institute. Canada pays more for commonly used generic medications than several peer nations, including Germany, New Zealand and Sweden, the study found.

- There has been "tremendous progress" in putting warnings on ciga- rette packaging around the world, with many countries increasing the size of warnings and requiring pictures, states a report by the Canadian Cancer Society. Picture warnings are required in 77 countries, covering nearly half the global population, up from 55 nations in 2012.

- Pharmaceutical retailers in British Columbia have threatened lawsuits against the College of Pharmacists of $\mathrm{BC}$ if it attempts to ban tobacco sales in drugstores. $\mathrm{BC}$ is the only province in Canada that permits stores with pharmacies to sell tobacco products.

- Quebec hopes to create 343 positions for family doctors and 156 for specialists in 2015, according to Quebec Minister of Health and Social Services Gaetan Barrette. Most positions will be in Montréal and western Quebec; however, 143 family physicians are leaving the province, meaning there will be a net gain of 200 family doctors.

- A rash of suspected heroin overdoses in Vancouver has been linked instead to fentanyl, according to a warning from the Vancouver Police Department. A previous warning had linked 12 recent overdoses to heroin.
- Ontario has promised \$12 million for mental health projects at colleges and universities. Priority will be given to projects that help students with addictions, those just arriving from high school and students from First Nations and Métis communities.

- Several Alberta Health Services employees complained about being pressured to attend seminars by Landmark, a self-improvement company that has been accused of using coercive and manipulative methods. Internal documents obtained by $\mathrm{CBC}$ News indicate that one human resources advisor warned that making employees attend the controversial seminars could be "seen as a form of harassment."

- Two Ontario patients with impaired vision became the first Canadians to receive "bionic eye" systems. The system consists of prostheses on the retinas and glasses with cameras that feed images to the implants.

- Flu clinics opened across Saskatchewan, and long lines to receive the flu vaccine were reported in several areas, including Saskatoon and Regina. - Roger Collier, CMAJ

CMAJ 2014. DOI:10.1503/cmaj.109-4924 